\title{
EFEKTIVITAS TROTOAR BERDASARKAN TINGKAT PELAYANAN TROTOAR DI KOTA MAKASSAR
}

\author{
Retno Puspaningtyas \\ Program Studi Teknik Sipil \\ Universitas Sembilanbelas November Kolaka \\ Jln. Pemuda No. 339, Kolaka \\ puspaning_tyas@usn.ac.id
}

\author{
Muhammad Aditya Achmad \\ Program Studi Teknik Sipil \\ Universitas Sembilanbelas November Kolaka \\ Jln. Pemuda No. 339, Kolaka \\ adith_achmad@yahoo.co.id
}

\begin{abstract}
This study aims to analyze the effectiveness of the sidewalk path on Jalan Dr. Ratulangi in Makassar City in accommodating pedestrian volumes. The procedure carried out in this study is in accordance with the measurement of the effectiveness of the sidewalk, which is stated by the sidewalk level of service. Data collection is done through observation, measurement, and documentation. The results of this study indicate that there is one point with a low sidewalk level of service, namely point 2 in the Dr. Ratulangi segment, with the level of service D. Based on these results, the City Government needs to rearrange the location of flower pots and tree lines and improve the sidewalk design. In addition, additional sidewalk complementary facilities are needed to increase community interest in walking.
\end{abstract}

Keywords: sidewalk; pedestrian volume; pedestrian; level of service.

\begin{abstract}
Abstrak
Penelitian ini bertujuan menganalisis efektivitas jalur trotoar di Jalan Dr. Ratulangi di Kota Makassar dalam menampung volume pejalan kaki. Prosedur yang dilakukan pada studi ini sesuai dengan pengukuran efektivitas trotoar, yang dinyatakan dengan tingkat pelayanan trotoar. Pengumpulan data dilakukan melalui observasi, pengukuran, dan dokumentasi. Hasil penelitian ini menunjukkan bahwa terdapat satu titik yang dengan tingkat pelayanan trotoar yang rendah, yaitu titik 2 di segmen Dr. Ratulangi, dengan tingkat pelayanan D. Berdasarkan hasil tersebut, Pemerintah Kota perlu menata ulang letak pot bunga dan jalur pepohonan serta memperbaiki desain trotoar. Selain itu, diperlukan penambahan fasilitas pelengkap trotoar untuk meningkatkan minat masyarakat untuk berjalan kaki.
\end{abstract}

Kata-kata kunci: trotoar; volume pejalan kaki; pedestrian; tingkat pelayanan.

\section{PENDAHULUAN}

Tingkat kepadatan lalu lintas di Kota Makassar sampai saat ini masih menjadi masalah, khususnya yang terkait dengan pertumbuhan kendaraan yang cukup tinggi. Pertumbuhan ini tidak saja menimbulkan masalah kemacetan lalu lintas, tetapi juga menimbulkan masalah lain, seperti kecelakaan lalu lintas, polusi udara, dan kebisingan. Dalam hal ini ruang gerak manusia, khususnya dalam berjalan, menjadi tersisihkan dengan semakin banyaknya jumlah kendaraan bermotor.

Perhatian pemerintah masih terarah pada pemenuhan kebutuhan kendaraan pribadi. Kondisi ini terlihat pada pembangunan beberapa ruas jalan, yang hanya membangun bagian jalan untuk kendaraan bermotor saja. Sedangkan ruang untuk manusia berjalan kaki kurang 
atau tidak diperhatikan, hilang, atau beralih fungsi menjadi ruang parkir dan ruang untuk pedagang kaki lima berjualan. Akibatnya ruang untuk berjalan kaki menjadi tidak tersedia.

Kondisi pedestrian di perkotaan semakin terancam, khususnya di daerah persimpangan jalan yang sebidang. Daerah ini merupakan bagian yang sukar dan rumit suatu sistem jaringan jalan. Di sini terjadi pertemuan antara kendaraan dan pejalan kaki, yang berpotensi untuk menimbulkan tundaan (delay), kecelakaan lalu lintas, dan kemacetan lalu lintas (Khisty dan Lall, 2003; Soepandji, 2010).

Hal yang menarik adalah bahwa di pusat Kota Makassar khususnya di ruas Jalan Dr. Ratulangi terdapat berbagai konflik bagi pedestrian dan terdapat jalur pedestrian yang tidak berfungsi sebagaimana mestinya. Trotoar yang ada dipenuhi oleh pepohonan dan pot bunga, yang dapat menghambat kelancaran sirkulasi pejalan kaki. Banyak pejalan kaki yang berjalan di lajur untuk kendaraan, karena trotoar dipenuhi oleh pot bunga. Selain itu, Jalan Dr. Ratulangi merupakan jalan arteri yang padat kendaraan bermotor, sehingga dapat membahayakan pejalan kaki jika berjalan di lajur jalan.

Permasalahan ruang pedestrian yang dapat diidentifikasi di ruas Jalan Dr. Ratulangi berupa pergerakan pejalan kaki yang terhambat karena adanya elemen pelengkap trotoar, seperti pepohonan, pot bunga, papan iklan, tempat sampah, dan tiang listrik, yang berada di atas trotoar. Selain itu, terjadi penyalahgunaan fungsi trotoar, yang menjadikan trotoar sebagai tempat parkir kendaraan. Berdasarkan hal-hal tersebut, rumusan masalah pada penelitian ini adalah bagaimana menentukan efektivitas trotoar Jalan Dr. Ratulangi berdasarkan tingkat pelayanan (Level of Service, LOS) trotoar.

\section{Pedestrian dan Karakteristiknya}

Pedestrian berasal dari bahasa Yunani, yaitu dari kata pedos, yang berarti kaki. Karena itu pedestrian dapat diartikan sebagai pejalan kaki atau orang yang berjalan kaki. Sedangkan jalan merupakan media di atas bumi yang dimaksudkan untuk memudahkan manusia berjalan kaki. Pedestrian dalam hal ini memiliki arti pergerakan atau perpindahan manusia dari satu tempat ke tempat lain sebagai tujuan dengan menggunakan moda jalan kaki. Secara harfiah, pedestrian berarti "person walking on the street ", atau orang yang berjalan di jalan.

\section{Fasilitas Pedestrian}

Fasilitas pedestrian, sebagaimana disebut dalam Perencanaan Teknis Fasilitas Pejalan Kaki (Kementerian PUPR, 2018), dapat dikelompokkan sebagai berikut:

1) Trotoar; yaitu jalur pejalan kaki yang terletak pada Ruang Milik Jalan, yang diberi lapisan permukaaan dengan elevasi yang lebih tinggi daripada permukaan perkerasan jalan, dan pada umumnya sejajar dengan jalur lalu lintas kendaraan.

2) Fasilitas penyeberangan; yang diperlukan untuk mengatasi konflik dengan moda dan angkutan lainnya. Menurut Fruin (1971), dalam merancang fasilitas bagi pejalan kaki, termasuk fasilitas penyeberangan, harus memperhatikan 7 sasaran utama, yaitu keselamatan (safety), keamanan (security), kemudahan (convenience), kelancaran (continuity), kenyamanan (comfort), keterpaduan sistem (system coherence), dan daya tarik (attrac- 
tiveness). Ketujuh faktor tersebut saling berhubungan (inter-related) dan saling tumpang tindih (overlapping). Berubahnya salah satu faktor akan memengaruhi faktor-faktor yang lain.

3) Fasilitas bagi penyandang cacat; untuk merancang fasilitas bagi penyandang cacat, perlu diketahui bahwa pedestrian yang difabel sensitif terhadap tekstur dan warna permukaan material, yang disebut dengan detectable warning. Alat pengarah atau rambu-rambu bagi penyandang cacat berfungsi untuk mengarahkan dan mendeteksi jalan di trotoar. Selain itu, kemiringan permukaan atau curb ramps sangat membantu kelompok pedestrian yang menggunakan kursi roda.

\section{Ruang Pejalan Kaki}

Ruang pejalan kaki pedestrian space) adalah rata-rata daerah yang tersedia untuk tiap pejalan pada suatu trotoar. Ruang pejalan kaki ini dinyatakan dalam meter persegi per orang. Secara skematis ruang pejalan kaki dapat dilihat pada Gambar 1 dan Gambar 2.

\section{BODY ELLIPSE}

\section{$0.50 \mathrm{~m}$ BODY DEPTH}

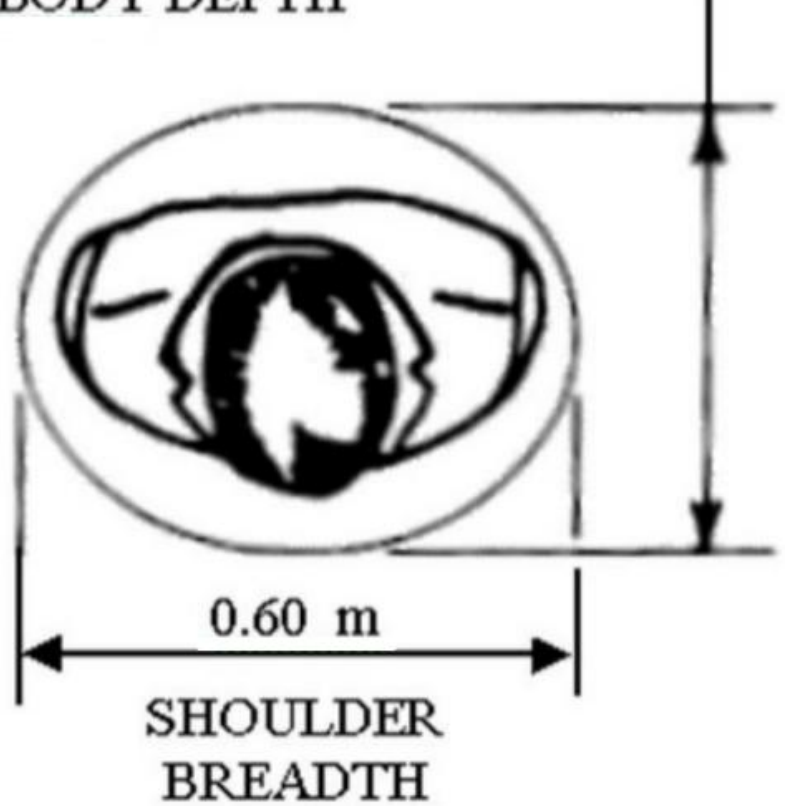

Sumber: Fruin (1971); FHWA (2002)

Gambar 1 Ruang yang Dibutuhkan Seorang Pejalan Kaki

\section{TINGKAT PELAYANAN TROTOAR}

Konsep tingkat pelayanan jalur berjalan pada dasarnya sama dengan konsep tingkat pelayanan yang digunakan untuk menentukan tingkat kenyamanan jalan. Pada konsep ini, 
faktor-faktor kenyamanan, seperti kemampuan untuk memilih kecepatan berjalan, mendahului, dan mencegah konflik dengan pejalan kaki lain, berkaitan dengan kepadatan dan volume pejalan kaki (TRB, 2000).
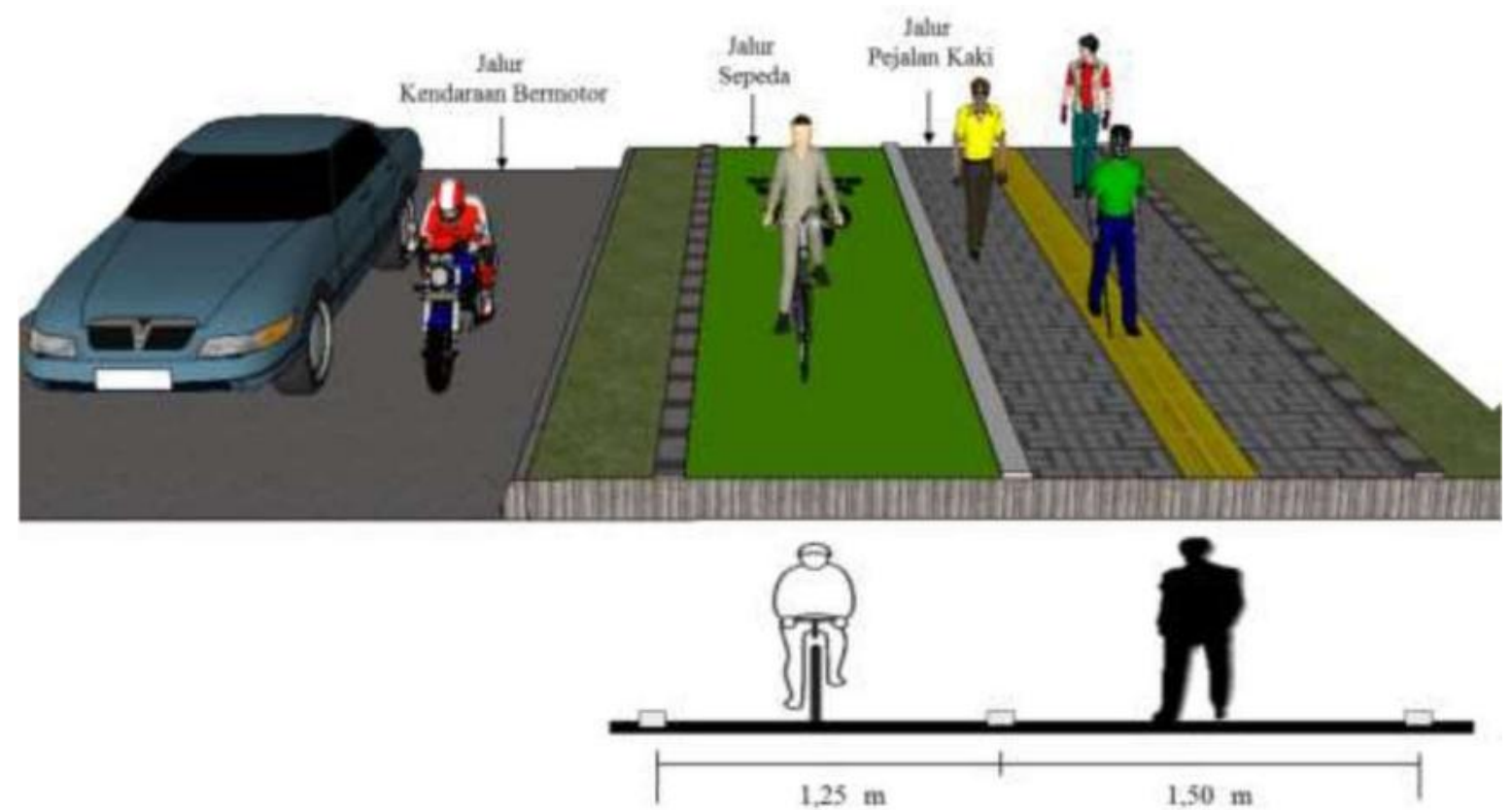

Sumber: Kementerian PUPR (2018)

Gambar 2 Ruang yang Dibutuhkan Seorang Pejalan Kaki

Pola arus dari pejalan kaki hampir sama dengan pola arus kendaraan bermotor. Apabila arus meningkat, kecepatan berjalan akan menurun. Apabila arus telah mencapai maksimum, kecepatan berjalan akan mendekati nilai nol. Ukuran kualitatif arus pejalan kaki serupa dengan yang digunakan untuk arus kendaraan, yaitu kebebasan untuk memilih kecepatan yang diinginkan untuk mendahului pejalan kaki lain.
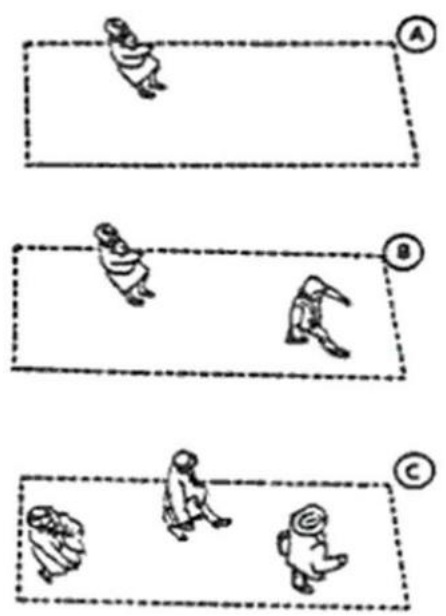

Sumber: Fruin (1971) dan TRB (2000)
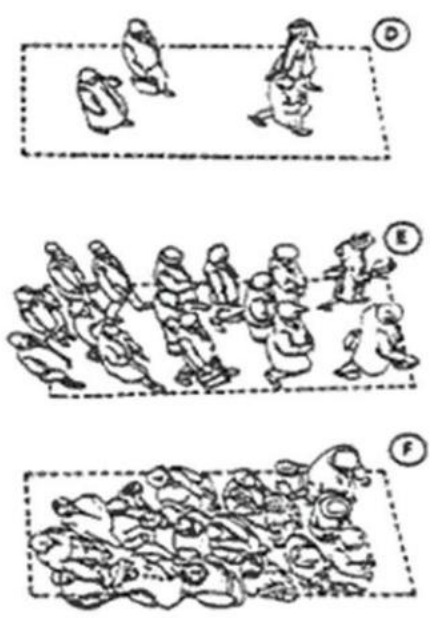

Gambar 3 Ilustrasi Tingkat Pelayanan Pejalan Kaki 
Secara umum, LOS dapat diukur dari kebebasan para pejalan kaki untuk memilih kecepatan berjalan yang diinginkan, atau untuk mendahului pejalan kaki lain yang berjalan lebih lambat. Standar pengukuran yang lain terkait dengan kemampuan seorang pejalan kaki untuk menyeberangi atau memotong arus pejalan kaki, berjalan dalam arah yang berlainan dengan arus pejalan kaki mayoritas, dapat melakukan manuver tanpa mengakibatkan konflik, dan mengubah kecepatan berjalan atau kecepatan melangkah, sebagaimana ditunjukkan pada Gambar 3.

\section{METODE PENELITIAN}

Pelaksanaan penelitian ini dimulai pada tanggal 3 Juni 2019 sampai dengan tanggal 8 Juli 2019. Pada waktu tersebut dilakukan survei kondisi eksisting trotoar, tata guna lahan, dan pola pergerakan pedestrian. Lokasi penelitian adalah ruas Jalan Dr. Ratulangi, di Kota Makassar.

Penetapan lokasi penelitian didasarkan pada pertimbangan bahwa lokasi tersebut berada pada jalan arteri dan memiliki jumlah pejalan kaki yang tinggi. Hal ini dapat diidentifikasi dari jenis pemanfaatan lahan atau tata guna lahan di sekitar lokasi. Jalan Dr. Ratulangi ini memiliki fasilitas pejalan kaki (trotoar), dengan letak elemen pelengkap trotoar dapat mengganggu dan menghambat pejalan kaki, serta volume dan kecepatan kendaraan cukup tinggi, sehingga berpotensi terjadi kecelakaan lalu lintas.

Data primer pada penelitian ini adalah data volume pedestrian 15 menitan pada segmen Dr. Ratulangi, data geometrik trotoar, data tata guna lahan, dan data elemen pelengkap jalur trotoar. Sedangkan data sekunder yang digunakan adalah berupa pedoman yang digunakan, termasuk Perencanaan Teknis Fasilitas Pejalan Kaki (Kementerian PUPR, 2018), Manual Kapasitas Jalan Indonesia 1997 (Direktorat Jenderal Bina Marga, 1997), Spesifikasi Trotoar SNI 03-2443-1991 (BSN, 1991), dan Perencanaan Trotoar (Departemen Pekerjaan Umum, 1998).

\section{TEKNIK ANALISIS DATA}

Analisis yang dilakukan adalah:

1) Mengobservasi dan mengukur dimensi lebar dan tinggi eksisting trotoar beserta elemenelemen pelengkapnya. Kemudian mengamati pergerakan pejalan kaki yang berada di segmen Sudirman dan Dr. Ratulangi berdasarkan jenis tata guna lahan di kawasan segmen-segmen tersebut.

2) Menghitung volume pejalan kaki, berupa data arus lalu lintas pejalan kaki (P) untuk menentukan tingkat pelayanan (LOS) trotoar dan lebar efektif jalur trotoar di titik penga- 
matan. Lebar jalur trotoar ditentukan berdasarkan arus pejalan kaki dengan menggunakan rumus:

$$
W=P W=\frac{P}{35}+1,5
$$

dengan:

$\mathrm{P}=$ Arus pejalan kaki (orang/menit/meter); dan

$\mathrm{W}=$ Lebar jalur pejalan kaki.

3) Melakukan analisis melalui perbandingan dimensi trotoar eksisting di setiap segmen dengan standar dimensi ideal trotoar.

4) Melakukan analisis pola pergerakan pejalan kaki untuk mengetahui karakteristik pengguna trotoar di Jalan Dr. Ratulangi.

\section{TINJAUAN UTAMA KAWASAN PENELITIAN}

Penggunaan lahan di Jalan Dr. Ratulangi didominasi oleh fungsi komersial, yaitu perdagangan, jasa pelayanan, dan perhotelan. Selain fungsi komersial terdapat pula beberapa bangunan dengan fungsi pendidikan. Ruas Jalan Dr. Ratulangi juga mempunyai potensi bangkitan dan tarikan perjalanan yang tinggi, karena ruas jalan tersebut merupakan rute angkutan umum. Jaringan jalan pada kawasan penelitian berpola grid, yang mana kondisi ini memudahkan mobilisasi atau pergerakan masyarakat yang berjalan kaki dan didukung oleh tata guna lahan campuran, sehingga setiap daerah dapat dijangkau dengan berjalan kaki.

Jalur pejalan kaki dapat dikatakan efektif apabila lebar jalur trotoar dapat melayani volume pejalan kaki pada waktu puncak (waktu padat) berdasarkan kegiatan dan fungsi bangunan sekitarnya (Ball, 2001; Khisty dan Lall, 2003).

Efektivitas trotoar dapat memengaruhi keamanan, kenyamanan, dan kesenangan pejalan kaki. Hal ini dapat dilihat dari ukuran trotoar, tinggi trotoar, ruang bebas trotoar, pembatas yang berupa kerb ataupun barrier, permukaan trotoar yang rata, tidak licin, dan suasana trotoar yang teduh. Indikator efektivitas trotoar ini mengacu pada faktor yang memengaruhi kegiatan pejalan kaki di perkotaan dan pedoman perencanaan jalur pejalan kaki. Efektivitas juga dapat diukur dari LOS trotoar itu sendiri. Trotoar direncanakan dengan tingkat pelayanan serendah-rendahnya $\mathrm{C}$.

\section{ANALISIS DATA TINGKAT PELAYANAN}

Tata guna lahan yang terdapat di segmen Dr. Ratulangi sangat beragam, yang meliputi fungsi-fungsi perkantoran, perdagangan, jasa, dan pendidikan. Tata guna lahan ini memengaruhi pola pergerakan pejalan kaki di ruang perkotaan (Khisty dan Lall, 2003). Volume pejalan kaki pada segmen ini juga dihitung setiap rentang waktu 15 menit, karena 
di Indonesia kegiatan berjalan kaki masih kurang diminati. Berdasarkan hasil pengamatan, diperoleh data, seperti yang terdapat pada Tabel 1 dan Tabel 2.

Tabel 1 LOS Trotoar Kanan pada Segmen Dr. Ratulangi

\begin{tabular}{ccccc}
\hline $\begin{array}{c}\text { Segmen } \\
\text { Dr. Ratulangi }\end{array}$ & $\begin{array}{c}\text { Volume Maks. } \\
\text { (org/15 menit) }\end{array}$ & $\begin{array}{c}\text { Lebar Efektif Trotoar } \\
\text { Eksisting }(\mathrm{m})\end{array}$ & $\begin{array}{c}\text { Tingkat Arus } \\
\text { (org/m/15 menit) }\end{array}$ & LOS \\
\hline Titik 1 & 8 & 0,8 & 10 & B \\
Titik 2 & 43 & 1,85 & 23,2 & C \\
Titik 3 & 11 & 1,56 & 7,1 & B \\
\hline
\end{tabular}

Tabel 2 LOS Trotoar Kiri pada Segmen Dr. Ratulangi

\begin{tabular}{ccccc}
\hline $\begin{array}{c}\text { Segmen } \\
\text { Dr. Ratulangi }\end{array}$ & $\begin{array}{c}\text { Volume Maks. } \\
\text { (org/15 menit) }\end{array}$ & $\begin{array}{c}\text { Lebar Efektif Trotoar } \\
\text { Eksisting }(\mathrm{m})\end{array}$ & $\begin{array}{c}\text { Tingkat Arus } \\
\text { (org/m/15 menit) }\end{array}$ & LOS \\
\hline Titik 1 & 4 & 2 & 2 & $\mathrm{~A}$ \\
Titik 2 & 25 & 0,6 & 41,7 & $\mathrm{D}$ \\
Titik 3 & 6 & 1 & 6 & $\mathrm{~A}$ \\
\hline
\end{tabular}

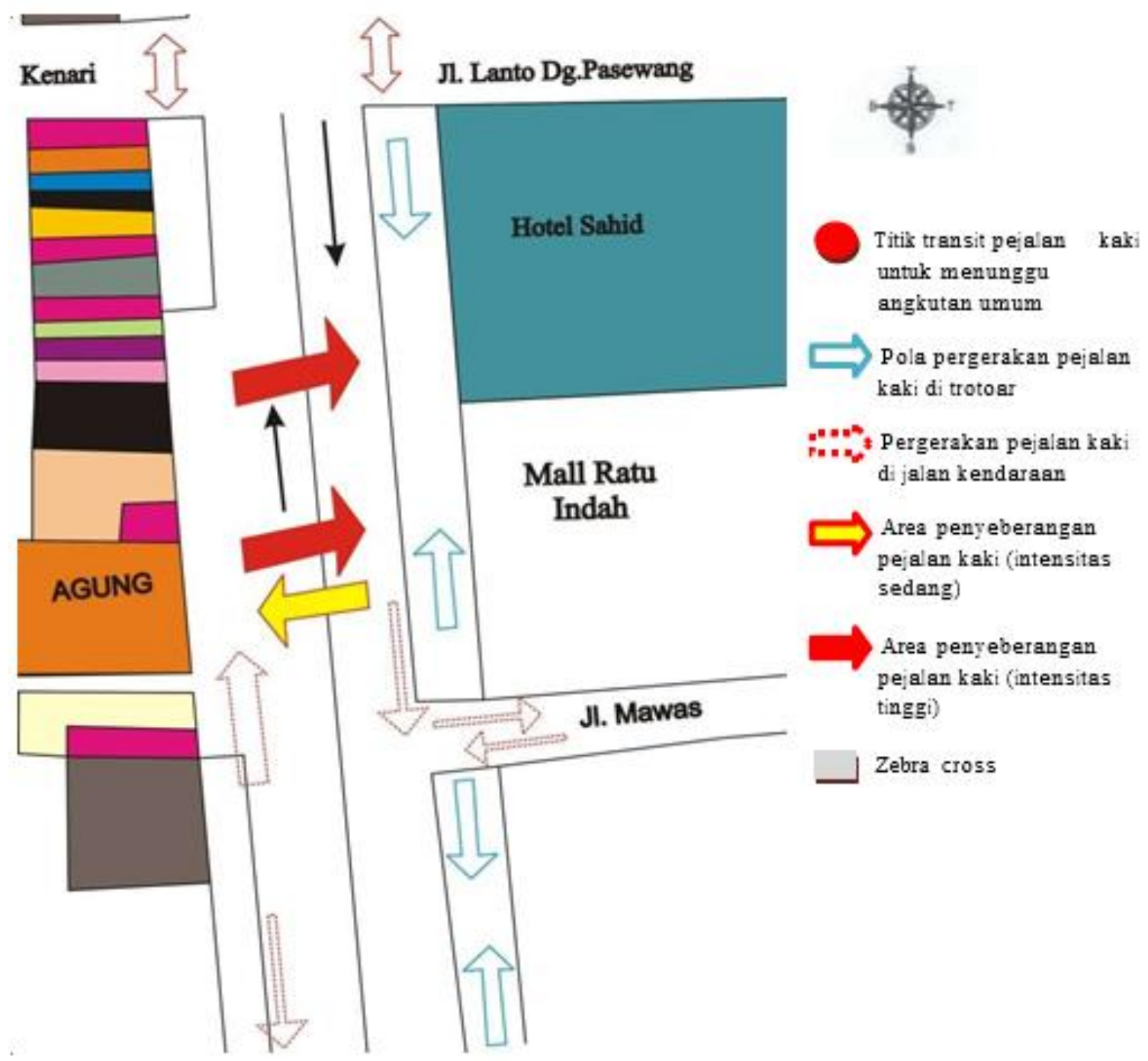

Gambar 4 Pola dan Arah Pergerakan Pejalan Kaki di Titik 2 Segmen Jln. DR Ratulangi 
Berdasarkan pengamatan di segmen Dr. Ratulangi terlihat bahwa volume pejalan kaki di trotoar sebelah kanan lebih besar dibandingkan dengan volume pejalan kaki di trotoar sebelah kiri. Pada trotoar sebelah kiri, volume pejalan kaki terbesar terjadi di titik 2 (MARIAgung) pada sore hari, yaitu 25 orang/15 menit. Volume pejalan kaki terbesar terdapat pada titik 1 (Kantor Bank Sulsel), terjadi pada hari Senin pagi dan hari Jumat siang, yaitu sebanyak 4 orang/15 menit. Sedangkan volume pejalan kaki terbesar di titik 3 (SD Kartika dan sekolah yayasan) terjadi pada hari Senin siang sebanyak 6 orang/15 menit.

Segmen Dr. Ratulangi merupakan segmen yang volume pejalan kakinya cukup besar. Namun hal ini tidak ditunjang oleh kondisi trotoar yang bagus dan nyaman. Trotoar di segmen Dr. Ratulangi banyak dipadati oleh pot bunga yang diletakkan di tengah-tengah jalur trotoar, sehingga mengganggu kelancaran arus perjalanan pejalan kaki. Selain pot bunga, deretan pepohonan besar juga terletak di tengah jalur trotoar dan terdapat pula becak dan pedagang kaki lima yang berjualan di atas trotoar segmen jalan tersebut.

\section{LEBAR TROTOAR IDEAL}

Lebar efektif minimum ruang pejalan kaki berdasarkan kebutuhan orang adalah 60 cm ditambah $15 \mathrm{~cm}$ untuk berjalan tanpa membawa barang. Dengan demikian kebutuhan total minimal untuk 2 orang pejalan kaki berjalan bersama atau 2 orang pejalan kaki berpapasan tanpa mengganggu jalur masing-masing adalah $150 \mathrm{~cm}$. Kebutuhan lebar trotoar dihitung berdasarkan volume pejalan kaki rencana (V). Volume pejalan kaki (V) dihitung berdasarkan survei penghitungan pejalan kaki yang dilakukan setiap interval 15 menit selama jam sibuk dalam satu hari untuk 2 arah.

\section{FASILITAS BAGI PENYANDANG CACAT}

Trotoar di segmen Dr. Ratulangi tidak dapat menunjang mobilisasi penyandang cacat, karena tidak terdapat ramp di semua titik pengamatan. Pada permukaan trotoar juga tidak terdapat tekstur tile untuk memandu para penyandang cacat. Selain itu, lebar efektif trotoar di seluruh titik pengamatan pada segmen Dr. Ratulangi sangat sempit, dengan lebar sekitar $1 \mathrm{~m}$ hingga 1,8 $\mathrm{m}$. Ukuran lebar ini hanya dapat menunjang pergerakan satu arah bagi para penyandang cacat yang menggunakan bantuan kursi roda.

\section{KESIMPULAN DAN SARAN}

Berdasarkan hasil pengamatan dan analisis yang telah dilakukan, dapat ditarik kesimpulan sebagai berikut: 
1) Tingkat Pelayanan (LOS) titik 2 Dr. Ratulangi MARI-Agung, di trotoar sebelah kanan berada pada level C, karena terdapat pot bunga di tengah jalur trotoar. Sedangkan di segmen Dr. Ratulangi trotoar dengan tingkat pelayanan rendah adalah di trotoar kiri di titik 2 MARI-Agung, dengan tingkat pelayanan D. Tingkat pelayanan ini lebih rendah daripada standar minimum perencanaan trotoar. Lebar efektif trotoar kiri di titik 2 Dr. Ratulangi ini sempit karena terdapat telepon umum dan trotoarnya tidak kontinyu akibat adanya jalur sirkulasi kendaraan menuju tempat parkir toko.

2) Lebar efektif trotoar eksisting tidak memadai dalam menampung volume dan arus pejalan kaki di semua titik di segmen Dr. Ratulangi, sehingga pejalan kaki tidak bebas untuk mendahului pejalan kaki lain maupun mengubah kecepatan berjalan.

Adapun saran yang dapat diberikan adalah sebagai berikut:

1) Perlunya penataan letak elemen-elemen pelengkap trotoar dan tata hijau yang berupa pepohonan dan pot bunga di sisi dalam ataupun di sisi luar trotoar, agar tidak menghalangi pejalan kaki di trotoar.

2) Pihak yang terkait agar menambah fasilitas jalur pejalan kaki yang dapat memudahkan mobilisasi pejalan kaki di ruang perkotaan.

3) Perlunya penambahan lebar trotoar, khususnya titik 2 Dr. Ratulangi-MARI di trotoar sebelah kiri, serta letak pot bunga dan pepohonan perlu ditata kembali.

4) Pemerintah perlu mengkaji ulang desain serta fasilitas pelengkap trotoar yang sudah ada agar dapat meningkatkan keamanan, kenyamanan, dan kesenangan pejalan kaki.

\section{DAFTAR PUSTAKA}

Badan Standardisasi Nasional. 1991. Spesifikasi Trotoar. SNI-03-2443-1991. Jakarta.

Ball, J.T. 2001. Transportation Engineering. New York, NY: McGraw Hill Professional.

Departemen Pekerjaan Umum. 1998. Perencanaan Trotoar. Pedoman Konstruksi dan Bangunan. Jakarta.

Direktorat Jenderal Bina Marga. 1997. Manual Kapasitas Jalan Indonesia (MKJI). Jakarta. Federal Highway Administration (FHWA). 2002. Pedestrian Facilities Users GuideProviding Safety and Mobility. Publication No. FHWA-RD-01-102. U.S. Department of Transportation. Washington, DC.

Fruin, J.J. 1971. Pedestrian Planning and Design. New York: Metropolitan and Association of Urban Designers and Environmental Planners..

Kementerian Pekerjaan Umum dan Perumahan Rakyat. 2018. Perencanaan Teknis Fasilitas Pejalan Kaki SE Menteri PUPR No. 02/SE/M/2018. Jakarta.

Khisty, C.J. dan Lall, B.K. 2003. Transportation Engineering: An Introduction. Upper Saddle River, NJ: Prentice Hall. 
Soepandji, W.W. 2010. Pejalan Kaki dan Perjalanannya: Studi Kasus Pejalan Kaki Usia Kanak-Kanak dan Usia Lanjut di Jalan Margonda Raya Depok. Skripsi tidak diterbitkan. Jakarta: Fakultas Teknik, Departemen Arsitektur, Universitas Indonesia.

Transportation Research Board (TRB). 2000. Highway Capacity Manual. Washington, DC: National Research Council. 